\title{
TUNJUK AJAR MELAYU; \\ Warisan Nilai Pada Bait-Bait Syair Gurindam Dua Belas Raja Ali Haji
}

Oleh H. Mulyadi

Abstract; Mystical literature is not only a part of the long tradition in Malay literature in archipelagos but also it is directly a integral part of policical, cultural and social practice that was conditioned, and if conditioned the discursive formation in society of Malay particularly in Pengengat IslandKepulauan Riau province, and widely in South East Asia area. Gurindam Dua Belas Raja Ali Haji is the Islamic literary work that is characterized typically by Sufism, writing by Raja Ali Haji, an intellectual, cultural observer, Moeslem leader in $19^{\text {th }}$ centuries in Pengengat Island. This Gurindam Dua Belas Raja Ali Haji is included al-irsyadi's literary work containing the didactic-educational message for ethical and moral reconstruction of life.

Kata kunci: Tunjuk Ajar Melayu, Raja Ali Haji, Gurindam 12 


\title{
TUNJUK AJAR MELAYU; \\ Warisan Nilai Pada Bait-Bait Syair Gurindam Dua Belas Raja Ali Haji
}

\author{
Oleh H. Mulyadi
}

\section{Pendahuluan}

Tata dunia saat ini sudah mengarah pada kehidupan gobal, dimana tata ruang yang ada sudah tidak ada lagi sekat-sekat yang membatasi kehidupan manusia. Dunia global juga sering dinamai dengan cyber space, ruang gerak dunia tanpa sekat, tanpa batas dan berubah secara cepat. Pengaruh-pengaruh luar begitu mudah merasuki dan memasuki disegala sisi kehidupan manusia seiring dengan kecepatan perkembangan teknologi dalam berbagai bidang, baik teknologi informasi maupun teknologi rekayasa yang dapat memudahkan kehidupan manusia.

Dunia global membuat tata kehidupan personal, sosial, budaya, ekonomi dan politik sudah menyatu dengan dunia luar, sehingga identitas yang asli dan batas-batas tentang semua itu menjadi kabur, bahkan identitas atau karakter manusia menjadi tidak jelas karena tergelincir pada suasana arus kehidupan yang begitu cepat berubah dari detik demi detik dan tidak menentu.

Dari sebuah kekaburan visi kehidupan ini, manusia dilanda krisis spritualitas, krisis moral, krisis etika dan krisis kepribadian dalam mentalitas kehidupan manusia. Sehingga arah kehidupan sering kali terjebak pada perilaku destruktif karena tidak mengenal identitas dirinya dan segala aspek yang melingkupinya. Disinilah masyarakat membutuhkan filter ${ }^{1}$ kehidupan agar tetap memiliki identitas dan tidak

${ }^{1}$ Filter adalah sebagai usaha selektif terhadap perkembangan sosial budaya, ekonomi dan politik agar kehidupan lebih konstruktif berdasar atas moral dan etika. Tanpa filter yang tangguh dapat mengakibatkan pergeseran dan perubahan pola pikit dan perilaku 
terombang ambing oleh kehidupan yang penuh persaingan keras dan perubahan yang begitu cepat.

Jatidiri merupakan identitas sekaligus modal budaya ${ }^{2}$ yang sangat signifikan bagi suatu bangsa untuk membangun sebuah peradaban dan karakter dalam bingkai mentalitas moralitas. Sebagai identitas ia menjadi orientasi dasar peradaban (sivilisasi). Sedangkan sebagai modal budaya ia membuka berbagai kemungkinan tentang potensi yang menentukan produk kebudayaan. Faktor penentu jatidiri buka hanya agama saja, melainkan juga sistem kepercayaan, dimana jatidiri merupakan sosok yang dibentuk dan dibangun dari nilai-nilai dasar mental berupa spritualitas yang ditransformasikan dalam tindakan kultur dalam bentuk karakter bermoralitas.

Menanamkan nilai-nilai pendidikan untuk mengkonstruksi identitas dan jatidiri peradaban itu dapat melalui mediasi penghayatan karya sastra. karena sastra sanggup dan mampu memberikan pengertian yang mendalam tentang tata nilai etis dan moral manusia dan memberikan interpretasi serta apresiasi terhadap peristiwa-peristiwa kehidupan. Sebab karya sastra memang tidak hanya sekedar untuk dinikmati, melainkan

yang dapat melecehkan nilai agama, budaya dan norma-norma yang hidup dalam masyarakat bahkan membahayakan kosmos kehidupan ini. Sebagai akibatnya, besar kemungkinan manusia dan masyarakat akan kehilangan nilai-nilai eksistensial yang luhur dan lambat laun akan kehilangan kepribadian dan jati dirinya. Siti Zahra Yundiafi, Muhammad Jaruki dan Mardianto, Antologi Puisi Lama Nusantara: Berisi Nasehat, (Jakarta: Yayasan Obor Ondonesia, 2003), hlm. 1.

${ }^{2}$ Budaya mempunyai arti yang sangat komplek atau multi demensional dimana kebudayaana dalah keseluruhan perilaku sosial manusia yang teratur oleh tata kelakuan masyarakat yang harus didapatkannya dengan belajar dan semuanya tersususn dalam kehidupan masyarakat. Jelasnya hakekat kebudayaan adalah interaksi dan sosialisasi kehidupan seluruh masyarakat, kebudayaan tersebut telah ada sebelum mulainya satu generasi bahkan ditransmisikan dari generasi kegenerasi berikutnya. Wakidul kohar, Komunikasi Antar Budaya Sebagai Metode Dakwah Untuk masyarakat Multi Etnis, (Makalah seminar Konferensi kajian Islam Indonesia, Program Pascasarjana IAIN/STAIN/UIN Se-Indonesia), (Yogyakarta: Bagian Proyek Peningkatan Kerjasama Luar Negeri Direktorat Jendral Kelembagaan Agama Islam Depag RI dan Program Pascasarjana IAIN Sunan kalijaga dan UIN Syarif Hidayatullah Jakarta: 12-14 Desember 2003), hlm. 9. 
perlu juga dimengerti, dihayati dan ditafsirkan. ${ }^{3}$ Karya sastra dapat dipandang sebagai satu cara manusia untuk menata kembali kehidupan lewat berbagai imajinasi dengan cara yang dirasakan mesra.

Sastra sebagai instrumen untuk mencapai "pemahaman yang imajinatif" mengenai alam kehdupan sosial keagamaan dan politik dimana sastra akan bersikap atau berfungsi kritis, etis, terapis dan konseptualis. Oleh karena itu, karya sastra sastrawan muslim memiliki peran penting dalam sepanjang sejarah terhadap penyebaran agama Islam dan juga pembentukan karakter masyarakat yang bermoralitas. Paling fundamental untuk diingat bahwa karya sastra tidak sebatas dakwah dalam artian sempit, tetapi juga sebagai pengajaran dan pondasi bagi kebudayaan kaum muslim, bahkan melalui karya sastralah kesadaran sejarah, penghayatan tasawuf dan keagamaan ditanamkan secara mendalam dilubuk hati umat Islam.

Melalui karya sastra pula nilai-nilai etika, moral dan pandangan hidup Islam dipribumisasikan dalam basis fundamental sosial-budaya masyarakat. ${ }^{4}$ Karya sastrawan Raja Ali Haji berupa Gurindan Dua Belas dimana didalamnya juga memuat hal-hal tersebut. Peran penting sastra Islam dan sastrawan muslim adalah dimana sastrawan muslim sering ditransformasikan menjadi simbol sosiologis-politis dan historis untuk

3 Zainuddin Fannie, Telaah Sastra, (Surakarta: Muhammadiyah Universitas Press: 2000), hlm. 67.

${ }^{4}$ M. Atar Semi mengatakan bahwa Sastra merupakan salah satu cabang kesenian yang selalu berada dalam peradaban manusia semenjak ribuan tahun yang lalu. Kehadiran sastra di tengah peradaban manusia tidak dapat ditolak, bahkan kehadiran tersebut diterima sebagai salah satu realitas social budaya. Hingga saat ini, sastra tidak saja dinilai sebagai sebuah karya seni yang memiliki budi, imajinasi, dan emosi, tetapi telah dianggap sebagai suatu karya kreatif yang dimanfaatkan sebagai konsumsi intelektual disamping konsumsi emosi. \Sastra lahir disebabkan dorongan dasar manusia untuk mengungkapkan dirinya, menaruh minat terhadap masalah manusia dan kemanusiaan, dan menaruh minat terhadap dunia realitas yang berlangsung sepanjang hari dan sepanjang zaman.

Sastra yang telah lahirkan oleh para satrawan diharapkan dapat memberi kepuasan estetik, kepuasan intelek dan kepuasan etik (moral). Dalam bait-bait syair Gurindam Dua Belas secara keseluruhan merupakan pesan-pesan hikmah dan kearifan hidup dan untuk hidup yang bersumberkan tata nilai Islam. Metode Penelitian Sastra, (Bandung: Angkasa, 2012), hlm. 1. 
menggambarkan perlawan terhadap sistem kekuasaan yang zalim, egosentris, monolitik, otoriter, serakah dan penuh dengan $\mathrm{KKN} .^{5}$

Karya sastra merupakan manifestasi kehidupan jiwa bangsa dari abad ke abad, didalam karya sastra terkandung ${ }^{6}$ nilai-nilai budaya yang mencerminkan kehidupan manusia pada waktu tertentu. Karya sastra merupakan khazanah ilmu pengetahuan dan budaya, oleh karena itu penghayatan terhadap karya sastra akan memberikan keseimbangan antara perolehan ilmu pengetahuan dan pembangunan jiwa baik mentalitas, karakter dan moralitas serta kepribadian masyarakat. Kedua hal itu dirasakan belum seimbang pada hal keselarasan antara keduanya sangat berperan dalam pembangunan setiap karakter manusia. ${ }^{7}$

\section{Sastra: Peran Gurindam Dua Belas dalam Bingkai Nilai}

Ruh karya seni dan sastra mengimplisitkan motivasi yang jauh lebih luas dan dalam, yaitu rekonstruksi asumsi-asumsi sosial, ${ }^{8}$ berbagai asumsi yang dikonfigurasikan secara verbal. Makna karya seni dan sastra terdiri atas hubungan-hubungan seimbang antara medium dengan pesan, bentuk

${ }^{5}$ Dimana sastra sebagai suatu ekspresi seni pengarang yang akan peka terhadap apa yang hidup dalam masyarakat dan yang memiliki daya observasi yang tajam dan peka pula terhadap masalah masyarakat maupun manusia anggota masyarakat dan menuangkan hasil pengamatan dan pengalaman sendiri ke dalam sebuah ungkapan sastra, dan karya sastranya dapat menggugah perasaan orang atau mendorong orang memikirkan masalah masyarakat maupun yang dilukiskannya. Maka, tentulah dapat diterima bahwa ada peran sastra dalam perubahan masyarakat. Mochtar lubis, Sastra dan Tekniknya, (Jakarta: Yayasan Obor Indonesia, 1997), hlm. 18.

${ }^{6}$ Karya sastra juga sarat dengan ajaran-ajaran relasional dengan Allah berupa ilmuilmu agama. Ibid, Mochtar Lubis, Sastra dan...,hlm. 20.

${ }^{7}$ Op. cit, Siti Zahra Yundiafi, Muhammad Jaruki dan Mardianto, Antologi Puisi Lama..., Hlm. 1.

${ }^{8}$ Karena bentuk dan isi karya sastra sebenarnya memang lebih banyak diambil dari fenomena sosial dibandingkan dengan seni yang lain, kecuali film, ini disebabkan sastra seringkali tampak terikat dengan momentum khusus dalam sejarah masyarakat. Tidaklah dapat dipungkiri bahwa karya sastra adalah fenomena sosial, karena pada hakekatnya sastra adalah produk sosial. Itulah sebabnya apa yang tergambar dalam karya sastra adalah sebuah entitas masyarakat yang bergerak, baik yang berkaitan dengan pola struktur, fungsi maupun aktivitas dan kondisi sosial budaya sebagai latar belakang kehidupan masyarakat pada saat karya sastra itu diciptakan. Op. cit, Zainuddin Fannie, Telaah...,hlm. 193. 
dengan isi sebagai keseimbangan totalitas artistik. Totalitas artistik menurut visi sosiologis sastra, tidak semata-mata terkandung dalam struktur intrinsik dalam "dunia dalam kata" menurut pemahaman strukturlisme, melainkan juga memiliki ciri-ciri transformasinya dalam struktur yang jauh lebih luas yaitu struktur sosial. ${ }^{9}$

Nilai-nilai lama dan budaya (lokal) yang ada mempunyai kemampuan dalam menyerap dan menterjemahkan gagasan ideal spritualisme universal dan akan sangat menentukan terbentuknya kualitas jatidirinya. Seideal apa pun spritualisme itu. Namun akan menjadi ilham yang kosong jika nilai-nilai budaya lokal gagal mentransformasikan dalam kehidupan mereka sehari-hari. ${ }^{10}$ Membangun jatidiri anak-anak bangsa dan masyarakat, berarti membangun kebudayaan yang sehat dan egiliter. Mengembalikan makna kebudayaan yang sesungguhnya yakni terbukanya berbagai peluang bagi anak-anak bangsa dan masyarakat untuk mengaktualisasikan seluruh potensinya berdasarkan integritas moral dan nilai-nilai pendidikan Islam. Dengan demikian, maka kita tidak akan takut menghadapi yang namanya arus globalisasi yang banyak memiliki efek perilaku negatif yang memasuki bilik-bilik kehidupan masyarakat.

Gurindam Dua Belas merupaka nilai-nilai yang menggunakan rujukan ajaran atau nilai-nilai agama Islam, budaya yang relevan dengan nilai-nilai agama Islam serta tidak melepaskan isi dan maknanya dalam kenyataan dan realitas sosial pada waktu itu. Selama ini nilai-nilai

${ }^{9}$ Bahwa karya sastra adlah refleksi masyarakat yang dipengaruhi oleh kondisi sejarah, karenanya sastra merupakan satu refleksi lingkungan budaya dan merupakan satu tes dialektika antara pengarang dengan situasi sosial yang membentuknya atau merupakan penjelasan suatu sejarah dialektika yang dikembangkan dalam karya sastra. Ibid, Zainuddin Fannie, Telaah..., Hlm. 132.

${ }^{10}$ Tata nilai baik yang islami maupun yang bukan adalah denyut jantung kehidupan masyarakat, sebab tata system value terkait erat dengan pola pikir yang hidup dalam masyarakat. Sehingga erat pula kaitannya dengan kebudayaan itu sendiri. Dalam perspektif ini, tata nilai yang melandasi gerak dan aktivitas individu dalam masyarakat ada hubungannya denga literatur, pola pendidikan, wasiat luhur, wejangan-wejangan, idiom-idiom, kitab suci, buku-buku dan lain sebagainya yang dipergunakan oleh masyarakat sebagai rujukan pola berpikir dan bertindak dalam kehidupan sehari-hari. M. Amin Abdullah, Studi Agama: Normativitas atau Historisitas, (Yogyakarta: Pustaka Pelajar, 1996), hlm. 216. 
tersebut membentuk simbol-simbol yang applicable dalam kehidupan budaya serta masyarakat setempat. Lebih lanjut lagi, karya sastra memiliki tujuan akhir yang sama yakni sebagai motivator ke arah aksi sosial yang lebih bermakna sebagai pencari nilai-nilai kebenaran. ${ }^{11}$

Nilai-nilai yang ada dalam Gurindam Dua Belas, telah mampu menjelaskan realitas kehidupan yang ada pada waktu itu dan malahan sampai sekarng nilai-nilai itu tetap aktual, karena ruh sastra (Gurindam Dua Belas) tidak pernah dan tidak akan melapaskan dirinya pada jasad nyata berupa kritik moralitas, pembentukan karakter masyarakat yang terpatri dalam pribadi sosial yang utuh.

Sebenarnya kesusastraan dapat berkembang dengan subur dan nilainilainya dapat dirasakan manfaatnya oleh umum, dimana kesusastraan sendiri mengandung potensi-potensi ke arah keluasan kemanusiaan dan semangat hidup semesta. Pada karya sastra yang berhasil didalamnya terkandung ekspresi total pribadi manusia yang meliputi tingkat-tingkat pengalaman biologi, sosial, intelektual dan religius. ${ }^{12}$ Nilai-nilai seperti itu sebagai observasi yang tajam dari pengarang yang dia tuangkan dalam karya sastra, realitas-realitas dalam simbolisasi karya sastra dapat memberikan interpretasi baru mengenai realitas yang terjadi dalam masyarakat. Membaca karya sastra memungkinkan seseorang mendapat masukan tentang manusia atau masyarakat serta peristiwa-peristiwa yang terjadi pada waktu itu, dan menimbulkan pikiran serta motivasi untuk berbuat sesuatu bagi manusia dan masyarakat sekitarnya sehingga dalam diri manusia sebagai pribadi dan anggota masyarakat akan timbul kepedulian terhadap apa yang dihadapi masyarakat.

Kepedulian terhadap masyarakat itu muncul, maka akan sendirinya ia melakukan berbagai hal untuk mengubah dan memperbaiki kehidupan yang terjadi di masyarakat. Jadi, sastra dapat berperan dalam proses perubahan masyarakat karena sastra lahir, tercipta dan berkembang dalam ruang dan waktu imajinatif dan tidak hampa dalam kehidupan

${ }^{11}$ Nyoman Kutha Ratna, Paradigma Sosiologi Sastra, (Yogyakarta: Pustaka Pelajar, 2003), hlm. 35.

12 Subagio Sastrowowardoyo, Sekilas Soal Sastra dan Budaya, (Jakarta: Balai Pustaka, 1992), hlm. 69. 
sosial dan budaya. Proses perubahan itu antara lain dapat: (1), menimbulkan kebiasaan membaca yang sangat dibutuhkan pada era kemajuan ilmu pengetahuan dan teknologi, (2), menimbulkan rasa simpati terhadap penderitaan dan berusaha untuk menanggulanginya, (3), memantapkan budaya yang beretika dan moral tinggi dalam kehidupan sebagai makhluk Tuhan, anggota masyarakat dan pribadinya, dan(4), mencintai kebenaran, keberaniaan, kejujuran, ketabahan dan ketangguhan yang sangat dibutuhkan dalam pembangunan karekter pribadi masyarakat dan peradaban. ${ }^{13}$ Gurindam dua belas telah mampu ditelaah sebagai nilai-nilai yang bisa dijadikan pembentukan sikap mental positif $^{14}$ dan menjadi filter dalam berbagai kerusakan moral, nilai, mentalitas, moralitas dan karekter pribadi masyarakat. Karena gurindam dua belas didalamnya penuh mengajarkan nilai-nilai ${ }^{15}$ yang dinyatakan dalam realitas kehidupan sebab dia lahir dari realitas kehidupan tersebut.

Karya sastra termasuk juga Gurindam Dua Belas selalu dan telah memberi pesan atau amanat untuk berbuat baik, dimana pembaca dan juga masyarakatnya diajak untuk menjunjung tinggi norma-norma moral dengan cara yang berbeda, sehingga sastra, filsafat dan agama sebagai

${ }^{13}$ Mochtar Lubis, Sastra dan Tekniknya, (Jakarta: Yayasan Obor Indonesia, 1997), hlm. 34 .

${ }^{14}$ Salah satu implikasi peran sastra adalah mengukuhkan nilai-nilai positif dalam pikiran dan perasaan manusia, Nani Tuloli, "Peranan Sastra dalam Masyarakat Modern" dalam Hasan Alwi dan Dedy Sugono, Telaah Bahasa dan Sastra, (Jakarta: Yayasan Obor Indonesia, 2002), hlm. 234.

${ }^{15}$ Dalam karya sastra baik puisi maupun prosa dimana butir-butir moral seperti itu banyak terungkap dan dapat dijadikan kajian, renungan dan pegangan bagi pembaca dan masyarakat, karya sastra harus mampu menggugah kesadaran masyarakat untuk menyerap dan mengolah pengaruh dari luar. Sebagai harapan kedepan, karya sastra tidak bersikap malu-malu, ragu-ragu atau curiga terhadap perkembangan iptek, sebab karya sastra justru dapat membantu mengembangkan sikap positif, mentalitas, moralities, etika dan karakter individu masyarakat terhdap perkembangan iptek yang tidak dapat dibendung pengaruhnya itu. Wardiaman Djojonegoro, Peningkatan Kualitas SDM melalui Pendidikan dan Kebudayaan, (Jakarta: Depertemen Pendidikan dan Kebudayaan, 1998), hlm. 425. 
sarana untuk menumbuhkan jiwa kemanusiaan yang halus dan manusia yang berbudaya. ${ }^{16}$

Sastra juga dapat dan memang mampu untuk membentuk watakwatak (karakter mentalitas pribadi yang bermoralitas) pribadi secara personal dan sosial. ${ }^{17}$ Sastra mampu juga menjadi sumber pengetahuan yang diajarkan disekolah dan bukan sekedara dinikmati sebagai hiburan. ${ }^{18}$ Untuk itulah, disinilah mulai bagaimana nilai-nilai sastra perlu pengajian dan penelitian yang khusus mendalam, agar mendapat nilainilai yang mampu dan mulai diterapkan dalam tingkah laku, sikap dan perubahan dalam kehidupan sehari-hari, agar nilai-nilai sastra bukan sebuah seni yang tinggi diatas menara gading serta berhiaskan artepakartepak majinatif impian yang berbungakan mimpi-mimpi pelangi hayalan, tetapi nilai-nilai sastra mampu dipatrikan dan ditanamkan berupa tugu karakter yang bermoralitas dalam konsep, pandangan, pikiran, paradigma dan kehidupan untuk melihatkan sederet cahaya

${ }^{16}$ Andi Zoelton (editor), Budaya Sastra, (Jakarta: Rajawali, 1984), hlm. 79.

17 Bahwa sastra sebagai karya seni hasil pergulatan bathin pengarang terhadap masalah-masalah kehidupan mengandung moral tinggi, karena itu ia dapat difungsikan secara efektif untuk membentuk watak dan moral manusia. Artinya adalah secara fakta historis bahwa karya sastra berisikan nilai-nilai kemanusiaan, nilai manusia, nilai kehalusan budi, nilai membangunan emosi, nilai agama dan nilai moralitas kehidupan. Karena sastra mampu berfungsi juga sebagai penyadar manusia akan kehadirannya yang bermakna baik dihadapan Pencipta maupun sesame umat manusia. Dengan kata lain, fungsi sastra adalah sebagai komunikasi imajinatif yang begitu mendalam antara realitas yang ada sehingga menjadi realitas ideal yang diinginkan, oleh karena itulah sastra penuh dengan sarat makan imajinatif yang mampu menampilkan dan menterjemahkan kedalam realitas kehidupan manusia. Sastra juga sebenarnya merupakan salah satu jalan untuk memperoleh kebenaran. A. Teeuw, Sastra: Tata Nilai dan Eksegesis, (Jakarta: Hanin Data, 1982), hlm. 7.

${ }^{18}$ Artinya adalah sastra sebagai sumberdaya dalam ikhtiar pendidikan niscaya akan mempercanggih wawasan seseorang, karena sastra tidak hampa makna, dari makna yang dikandungnya itulah kita mungkin menemukan berbagai nilai kehidupan serta pandangan hidup yang dilatari cakrawala yang kian meluas bentangannya, hal itu pada gilirannya berarti diperkaya wawasan seseorang oleh terpaan sastra, karena itu keakraban dengan sepatutnya mendapat perhatian dalam upaya pendidikan pada umumnya. Fuad Hasan, Catatan Perihal Sastra dalam Pendidikan, (Jakarta: Fakultas Sastra Universitas Indonesia, 1993), hlm. 6. 
mulia berupa; sosial, ${ }^{19}$ berbangsa, berkepribadian, berperadaban dan bermasyarakat yang memijak tanah realitas hidup.

Raja Ali Haji merupakan orang Melayu yang produktif menulis, dia berbeda dengan penulis saat itu karena dia sungguh piawai dalam menyuguhkan pesan pesan moral dalam dataran etika Islam. Karya-karya Raja Ali Haji sangat berakar kuat pada tradisi-tradisi Melayu ${ }^{20}$ dan ajaranajaran dan nilai-nilai luhur agama Islam. Anthony Reid dan David Marr mengatakan bahwa dalam karya ini (Gurindam Dua Belas) sangat berakar kuat pada tradisi kesusastraan Melayu dan Islam yang mencerminkan isinya tentang kehidupan tradisional, adat, agama yang arif dan nilai-nilai kemanusiaan serta ketuhanan. ${ }^{21}$

Raja Ali Haji adalah seorang cendikiawan ${ }^{22}$ terkenal dikalangan orang Melayu, dan dia adalah seorang sastrawan pertama dalam kesustraan yang karyanya dicetak. ${ }^{23}$ Adapun Gurindam Dua Belas merupakan karya sastra yang isinya, baik bait-bait syairnya berisi tentang

19 Secara sosiologis, tugas karya sastra tidak terkandung didalam karya tersebut, melainkan diluarnya, yaitu dalam struktur social, karena itu pula karya sastra dikatakan sebagai slah satu alat untuk melipat gandakan hubungan-hubungan social. Sebab karya sastra selalu berusaha menemukan dimensi-dimensi tersembunyi dalam kehidupan manusia. Dimensi-dimensi yang tidak terjangkau oleh kulaitas evidensi empiris, bahkan oleh instrument laboraterium struktur perilaku, struktur ide dan berbagai kecenderungan social, seperti yang tampak dalam struktur permukaan, tetapi dengan cara-cara melacaknya dari dan melalui sudut pandangan struktur yang mendasarinya. Op.cit, Nyoman Kutha Ratna, Paradigma Sosiologi...,hlm. 212-214.

20 Telah ditemukan besarnya peranan agama Islam dalam pembinaan dan peningkatan martabat sastra Melayu. Suwardi MS, Dari Melayu ke Indonesia (Peranan Kebudayaan Melayu dalam Memperkokoh Jati Diri Bangsa, (Yogyakarta: Pustaka Pelajar, 2008), hlm. 44.

${ }^{21}$ Anthony Reid dan David Marr, Dari Raja Ali Haji hingga Hamka: Indonesia dan Masa Lalunya, (Jakarta: Grafiti Pers, 1983), hlm. 98-99.

22 Suwardi MS mengatakanb bahwa Raja Ali Haji adalah salah seorang ynag bisa dikatakan dia merupakan tokoh tasawuf yang telah mnenghasilkan karya besar dalam membina dan mengembangkan kesusastraan Melayu sehingga mencapai martabat yang tinggi dalam lingkungan sastra dunia. Ibid, Dari Melayu ke ......,hlm. 44.

${ }^{23}$ Barbara Watson Andaya dan Virginia Matheson, Raja Ali Haji: Antara Pemikiran Islam dan Tradisi Melayu, dalam Al-Hikmah, Jurnal Studi Islam, No. 14 Vol. VI/ Thn. 1995, (Bandung: Yayasan Mutharida, 1995), hlm. 112. 
nesehat-nasehat, pesan-pesan moral dan etikan Islam yang bersifat edukatif untuk manusia pada umumnya, kepemimpinan, anak, orang tua, murid, guru, pria, perempuan, suami istri, muda mudi dan masyarakat serta nilai-nilai yang lain.

Sujarwanto mengatakan bahwa, salah satu karya sastra monumental dalam sejarah sastra adalah gurindam dua belas karya Raja Ali haji, dimana karyanya ini penuh dengan nilai-nilai pendidikan Islam, pesanpesan moral etis dalam kehidupan masyarakat, oleh sebab itu Hasan Junus menjelaskan bahwa gurindam dua belas bukan saja bernilai sastra dan puisi yang tinggi, tetapi karya ini juga dapat digolongkan dalam "Syi'ar Irsyadi" 24 atau puisi didaktik, yang bersifat nasehat dan petunjuk untuk kehidupan yang diridhai Allah. ${ }^{25}$

\section{Tunjuk Ajar Melayu: Warisan Nilai-Nilai dalam Gurindam Dua Belas Raja Ali Haji.}

Gurindam Dua Belas merupakan karya sastra pada abad ke-19 melalui mata pena dan olah pengetahuan dan pengalaman Raja Ali haji yang sarat dengan ajaran-ajaran etika dan moral (tunjuk ajar Melayu). Dimana pendidikan etika dan moral yang terkandung dalam Gurindam Dua Belas bersifat universal yang berfungsi sebagai pagar moral keluhuran rohani dan perilaku hidup dimana Gurindam Dua Belas karya sastra yang bait-bait syairnya berisikan tentang nasehat-nesehat, pesa-pesan moral dan etika Islam yang bersifat edukatif untuk manusia pada umumnya, pemimpin, anak, orang tua, murid, guru, pria, perempuan dan sebagainya. Karena karya ini berakar kuat tradisi kesusastraan Melayu dan

${ }^{24}$ Fungsi didaktik sastra yang terpenting adalah membudayakan umat manusia dengan nilai-nilai ideal yang mampu menjadi fondasi moral, intelektual, spiritual bagi tegaknya masyarakat dari kehidupan berbangasa yang damai, bahagia dunia dan akhirat. Hal ini menjadi nyata karena setiap karya sastra tentu mengandung nilai-nilai katarsis yang merupakan salah satu misi terpentingnya. Sujarwanto, Fungsi Didaktik Sastra dalam Pembangunan Mental Spritual dan Integritas manusia Indonesia, dalam Bahasa dan Sastra Indonesia (Menuju Peran Transformasi Sosial Budaya Abad XXI), (Yogyakarta: Gama Media, 2002), hlm. 505-506.

25 Hasan Junus, Raja Ali Haji Budayawan di Gerbang Abad XX, (Pekanbaru: Universitas Islam Riau Press, 1988), hlm. 114. 
Islam yang mencerminkan kehidupan tradisional, adat dan agama yang arif dan berkemanusiaan dan berketuhanan. ${ }^{26}$

Dimana aspek nilai-nilai moral dan etika pendidikan Islam dalam Gurindam Dua Belas, secara makro dapat dibagi atau klasifikasikan dalam beberapa sspek makro yaitu: (pertama). Aspek pendidikan syari'at sebagaimana secara eksplisit atau tersurat secara jelas dalam Gurindam Dua Belas pasal kedua, pasal kesembilah, pasal kesepuluh dan sebagian pada pasal ke dua belas. (kedua). Aspek sufistik, yaitu aspek pendidikan yang menekankan pada pola perilaku dan proses pembentukkan karakter atau sifat agar terhindar dari sifat yang tercela yang dapat mengotori hati manusia. Aspek pendidikan dalam bidang bidang ini seperti yang terdapat dalam bunyi bait-bait syair Gurindam Dua Belas pada pasal ketiga, pasal keempat dan pasal kedelapan. (ketiga). Aspek pendidikan etika dalam mencari ilmu pengetahuan seperti yang terdapat dalam Gurindam Dua Belas pada pasal yang kelima dan sebagian pada pasal yang kedua belas. (keempat). Aspek pendidikan politik sebagaimana terdapat dalam pasal kesebelas danb sebagian dari p[asal yang kedua belas. Jadi tidak dapatlah kita menutup mata dan memungkiri lagi apalagi menyangkal bahwa memang Gurindam Dua Belas isi bait-bait syair penuh dengan Tunjuk $\mathrm{Ajar}^{27}$ buat siapa pun yang begitu lengkap dan menakjubkan untuk kita pelajari dan hayati.

Peratama, tunjuk ajar Gurindam Dua Belas mengenai pelajaran dasar tasawuf. Perhatikanlah bunyi bait-bait syair Gurindam Dua Belas pada pasal pertama ini:

${ }^{26}$ Ibid, Anthony Reid dan David Marr, Dari Raja...... hlm. 98-99.

27 Tenas Effendi mengatakan yang dimaksud dengan Tunjuk Ajar adalah segala jenis petuah, petunjuk, nasihat, amanah, pengajaran, dan contoh teladan yang bermanfaat bagi kehidupan manusia dalam artian luas. Menurut orang tua Melayu, :Tunjuk Ajar Melayu adalah segala petuah, amanah, suri teladan, dan nasihat yang membawa manusia ke jalan yang lurus dan diridhai Allah, yang berkahnya menyelamatkan manusia dalam kehidupan didunia dan kehidupan di akhirat. Tunjuk Ajar Melayu (ButirObutir Budaya Melayu Riau),(Yogyakarta: AdiCita, 2004), hlm. 7. 
Barang siapa tiada memegang agama ${ }^{28}$

Sekali-kali tiada boleh dibilangkan nama ${ }^{29}$

Barang siapa mengenal yang empat

Maka yaitulah orang yang ma' rifat ${ }^{30}$

Barang siapa mengenal diri

Maka telah mengenal akan Tuhan yang bahari

Barang siapa mengenal dunia

Tahulah ia barang yang terpedaya

Barang siapa mengenal akhirat

Tahulah ia dunia mudharat.

Bait syair Gurindam Dua Belas pada pasal pertama ini begitu kaya akan nilai-nilai filosofi Islam, terutama kainnya dengan nilai-nilai syari'at dan tasawuf.

Kedua, Tunjuk ajar Gurindam Dua Belas Mengenai Pelajaran Inti Ajaran Agama Islam. Perhatikanlah bunyi bait-bait syair Gurindam Dua Belas pada pasal kedua ini:

Barangsiapa yang meninggalkan sembahyang

Seperti rumah tiada bertiang

Barangsiapa yang meninggalkan puasa

Tidaklah mendapat dua termasa

Barangsiapa yang meninggalkan zakat

28 "Seseungguhnya agama disisi Allah ialah Islam" (QS. Ali-Imran (3): 19). Dan "Pada hari ini telah Ku sempurnakan bagimu agamamu dan telah Aku cukupkan kepadamu nikmat-Ku, dan telah Aku ridhai Islam itu jadi agamamu” (Al-Maidah (5): 3).

29 "Barangsiapa yang mencari agama selain Islam, tidak akan diterima daripadanya dan akhirat termasuk orang yang merugi”. (Ali-Imran (3): 85).

${ }^{30}$ Menurut Hasan Yunus berdasar berbagai referensi tasawuf, makna yang empat itu adalah syari'at, tarikat, hakikat dan akhirat. Ibid, Raja Ali Haji:" Budayawan Di Gerbang ..... hlm. 114 . 
Tiadalah hartanya beroleh berkat

Barangsiapa yang meninggalkan haji

Tiadalah ia menyerpunakan janji.

Ketiga, Tunjuk ajar Gurindam Dua Belas mengenai pelajaran menjaga anggota tubuh dari sifat-sifat yang tidak baik. Perhatikanlah bunyi bait-bait syair Gurindam Dua Belas pada pasal ketiga ini:

Apabila terpelihara mata

Sedikitlah cita-cita

Apabila terpelihara kuping

Khabar yang jahat tiadalah damping

Apabila terpelihara lidah

Niscaya dapat daripadanya faedah

Bersungguh-sungguh engakau memeliharakan tangan

Daripada segala berat dan ringan

Apabila perut terlalu penuh

Keluarlah fi'il yang tiada senonoh

Annggota tengah hendaklah ingat

Disitulah banyak orang yang hilang semangat

Hendaklah peliharakan kaki

Daripada berjalan yang membawa rugi.

Perhatikanlah bunyi bait-bait syair Gurindam Dua Belas pada pasal keempat ini:

Hati itu kerajaan did alam tubuh

Jikalau zalim segala anggotapun rubuh

Apabila dengki sudah bertanah

Datang daripdanya beberapa anak panah 
Mengumpat dan memuji hendaklah pikir

Disitulah banyak orang tergelincir

Pekerjaan marah jangan dibela

Nanti hilang akal dikepala

Jika sedikit pun berbuat bohong

Boleh diumpamakan mulutnya pekung

Tanda orang yang celaka

Aib dirinya tiada ia sangka

Bakhil jangan diberi singgah

Itulah perompak yang amat gagah

Barangsiapa yang sudah besar

Janganlah kelakuannya membuat kasar

Barangsiapa perkataan kotor

Mulutnya itu umpama ketor

Di manalah salah diri

Jika tidak orang lain yang berperi

Pekerjaan takabur jangan direpih

Sebelum mati didapat juga sepih.

Pasal ketiga dan keempat Gurindam Dua Belas mengandung muatan-muatan kualitas kepribadian seseorang dalam kehidupan. Dasardasar moralitas hidup bagi seseorang yang menginginkan kesselamatan diri, oleh karena itu harus menjaga semua anggota tubuh dari segala perbauatan yang dapat menjerumuskan ke dalam kemaksiatan atau dosa, yang merendahkan derajat manusia yang berketuhanan. Kenapa harus kita jaga anggota tubuh kita, adalah untuk kita sebagai manusia menjadi manusia yang mempunyai peradaban dan mendapatkan kemuliaan disisi manusia dan Tuhan. 
Kemepat, Tunjuk ajar Gurindam Dua Belas mengenai pelajaran Mencari relasi yang tepat dan benar. Perhatikanlah bunyi bait-bait syair Gurindam Dua Belas pada pasal keenam ini:

Cahari oleh mu akan sahabat

Yang boleh dijadikan obat

Cahari oleh mu akan guru

Yang boleh tahukan tiap seteru

Cahari oleh mu akan istri

Yang boleh menyerahkan diri

Cahari oleh mu akan kawan

Pilih segala orang yang setiawan

Cahaei oleh mu akan abdi

Yang ada baik sedikit budi.

Pasal keenam dari Gurindam Dua Belas menekankan signifikasi akan pentingnya sebuah jalinan relasional. Dimana anjuran untuk memilih hubungan dengan manusia yang tepat dan benar, karena kalau tidak tepat kita memilih relasi, maka bukan membawa pengaruh yang baik bagi kita tetapi malahan dikemudian harinya akan menghancurkan dan merendahkan kita sendiri.

Kelia, Tunjuk ajar Gurindam Dua Belas mengenai pelajaran Hormat kepada orang tua dan orang tua mendidik dengan baik anaknya. Perhatikanlah bunyi bait-bait syair Gurindam Dua Belas pada pasal kesepuluh ini:

Dengan bapa jangan durhaka

Supaya Allah tidak murka

Denganibu hendaklah hormat

Supaya badan dapat selamat

Dengan anak janganlah lalai 
Supaya boleh naik ketengan balai

Dengan kawan hendaklah adil

Supaya yangannya jadi kapil.

Gurindam Dua Belas pasal kesepuluh ini berkaitan dengan moralitas dan etika anak poada orang tuanya serta kewajiban moral orang tua pada anak. Secara normative, hal ini merupakan pelaksanaan ajaran Al-Qur'an tentanng kewajiban anak berbuat baik kepada orang tuanya serta kewajiban orang tua pada pendidikan anaknya.

Keenam, Tunjuk ajar Gurindam Dua Belas mengenai pelajaran Menjaga amanat, pemimpin yang adil, menghargai profesional dan kompetensi seseorang. Perhatikanlah bunyi bait-bait syair Gurindam Dua Belas pada pasal kedua belas ini:

Raja mufakat dengan menteri

Seperti kebun berpagarkan duri

Betul hati kepada raja

Tanda jadi sebaarang kerja

Hokum adil atas rakyat

Tanda raja beroleh 'inayat

Kasihkan orang yang berilmu

Tanda rahmat atas dirimu

Hormat akan orang yang pandai

Tanda mengenal kasa dan cindai

Ingatkan dirinya mati

Itulah asal berbuat bakti

Akhirat itu terlalu nyata

Kepada hati yang tidak buta

\section{Kesimpulan}

272 Jurnal Madania: Volume 8 : 2, 2018 (e-ISSN 2620-8210|p-ISSN 2088-3226) 
Gurindam Dua Belas merupakan wujud ajaran edukatif atau oleh Hasan Junus menjelaskan bahwa Gurindam Dua Belas bukan saja bernilai sastra dan puisi yang tinggi, tetapi karya ini juga dapat digolongkan dalam "Syi'ar Irsyadi" atau puisi didaktik, yang bersifat nasehat dan petunjuk untuk kehidupan yang diridhai Allah. Dimana Gurindam Dua Belas juga merupakan karya sastra sufistik yang bukan saja bagian dari tradisi panjang dalam kesusastraan Melayu, melainkan secara langsung menjadi bagian internal dari praktik budaya sosial dan politik yang terkondisi dan mengkondisikan formasi diskursif masyarakat Melayu.

Wujud edukasi Gurindam Dua Belas yang berkaitan dengan nilainilai pendidikan Islam yaitu dalam bentuk panduan moral dan etika didalam berbagai bidang kehidupan dan hidup pada masyarakat Melayu melalui praktek budaya, sosial dan keagamaan. Aplikasi muatan pendidikan atau Tunjuk Ajar Gurindam Dua Belas ini dalam prakteknya didasari atas pandangan ideology Islam, sehingga ideologi Islam yang bersifat aplikatif dalam mengkontruksi system social budaya masyarakat (terutama masyarakat Pulau Penyengat). Tapi diharapakan bukan untuk masyarakat Pulau Penyengat saja hendak nilai-nilai Gurindam Dua Belas menjadi basis hidup dan kehidupan seluruh masyarakat, individu dan peradaban yang beradab. 


\section{Referensi}

A. Teeuw, Sastra: 1982, Tata Nilai dan Eksegesis, Jakarta: Hanin Data.

Andi Zoelton (editor), 1984, Budaya Sastra, Jakarta: Rajawali.

Anthony Reid dan David Marr, 1983, Dari Raja Ali Haji hingga Hamka: Indonesia dan Masa Lalunya, Jakarta: Grafiti Pers.

Barbara Watson Andaya dan Virginia Matheson, 1995, Raja Ali Haji: Antara Pemikiran Islam dan Tradisi Melayu, dalam Al-Hikmah, Jurnal Studi Islam, No. 14 Vol. VI/ Thn. 1995, Bandung: Yayasan Mutharida.

Fuad Hasan, 1993, Catatan Perihal Sastra dalam Pendidikan, Jakarta: Fakultas Sastra Universitas Indonesia.

Hasan Junus, 1988, Raja Ali Haji Budayawan di Gerbang Abad XX, Pekanbaru: Universitas Islam Riau Press.

M. Amin Abdullah, 1996, Studi Agama: Normativitas atau Historisitas, Yogyakarta: Pustaka Pelajar.

M. Atar Semi, 2012, Metode Penelitian Sastra, Bandung: Angkasa.

Mochtar lubis, 1997, Sastra dan Tekniknya, Jakarta: Yayasan Obor Indonesia.

Nani Tuloli, 2002, "Peranan Sastra dalam Masyarakat Modern" dalam Hasan Alwi dan Dedy Sugono, Telaah Bahasa dan Sastra, Jakarta: Yayasan Obor Indonesia.

Nyoman Kutha Ratna, 2003, Paradigma Sosiologi Sastra, Yogyakarta: Pustaka Pelajar.

Subagio Sastrowowardoyo, 1992, Sekilas Soal Sastra dan Budaya, Jakarta: Balai Pustaka.

Suwardi MS, 2008, Dari Melayu ke Indonesia (Peranan Kebudayaan Melayu dalam Memperkokoh Jati Diri Bangsa, Yogyakarta: Pustaka Pelajar. 
Tenas Effendi 2004, Tunjuk Ajar Melayu (Butir-butir Budaya Melayu Riau),Yogyakarta: AdiCita.

Wakidul kohar,2003, Komunikasi Antar Budaya Sebagai Metode Dakwah Untuk masyarakat Multi Etnis, (Makalah seminar Konferensi kajian Islam Indonesia, Program Pascasarjana IAIN/STAIN/UIN Se-Indonesia), (Yogyakarta: Bagian Proyek Peningkatan Kerjasama Luar Negeri Direktorat Jendral Kelembagaan Agama Islam Depag RI dan Program Pascasarjana IAIN Sunan kalijaga dan UIN Syarif Hidayatullah Jakarta: 12-14 Desember.

Wardiaman Djojonegoro, 1998, Peningkatan Kualitas SDM melalui Pendidikan dan Kebudayaan, Jakarta: Depertemen Pendidikan dan Kebudayaan.

Zahra Yundiafi, Muhammad Jaruki dan Mardianto, 2003, Antologi Puisi Lama Nusantara: Berisi Nasehat, Jakarta: Yayasan Obor Indonesia.

Zainuddin Fannie, 2000, Telaah Sastra, Surakarta: Muhammadiyah Universitas Press.

H. Mulyadi, M.Si adalah Dosen Tetap Jurusan Pendididikan Agama Islam STAI Auliaurrasyidin.Email : mulyadihusnihasimy@gmail.com 